\title{
Pencapaian Fase Embriosomatik Manggis (Garcinia mangostana L.) dengan Penambahan Thidiazuron dalam Medium Setengah MS Cair
}

DOI 10.18196/pt.2016.053.25-31

\author{
Innaka Ageng Rineksane
}

Program Studi Agroteknologi, Fakultas Pertanian, Universitas Muhammadiyah Yogyakarta, Jl. Lingkar Selatan, Kasihan, Bantul, Yogyakarta 55183; Email: rineksane@gmail.com

\begin{abstract}
ABSTRAK
Permintaan manggis yang meningkat tidak diiringi dengan produksinya disebabkan manggis masih diusahakan secara konvensional. Upaya perbanyakan manggis dilakukan melalui embriogenesis somatik. Penelitian ini bertujuan menguji penggunaan Thidiazuron dengan konsentrasi berbeda dalam medium 1⁄2 MS untuk mencapai fase embriosomatik manggis dari kalus asal biji. Penelitian terdiri dari 2 eksperimen. Eksperimen 1 : Kalus embriogenik seberat 1 g dari medium MS padat yang mengandung Thidiazuron (0,1; 0,5; dan 1 mg/l) dan 2,4-Dichlorophenoxy acetic acid (4,6,8 dan 10 mg/l) disubkultur ke dalam medium 1/2 MSO cair. Eksperimen 2 : Kalus embriogenik seberat 1 g dari medium MS padat yang telah dihomogenisasi dalam medium 1⁄2 MSO cair selama 2 minggu, disubkultur ke dalam medium 1⁄2 MS cair yang mengandung Thidiazuron (0, 1, 2, 4 dan 8 mg/L) dan Casein hydrolysate 500 mg/L. Hasil penelitian menunjukkan kalus embriogenik manggis yang disubkultur ke dalam medium 1/2 MSO cair mampu membentuk kultur suspensi sel. Struktur embrio somatik berupa globular, hati dan torpedo telah terbentuk dalam waktu 8 minggu pada suspensi sel yang diperoleh dari kalus yang sebelumnya ditumbuhkan pada medium 1⁄2 MS padat yang mengandung 10 mg/L 2,4-D dan 1 mg/L Thidiazuron. Kultur suspensi dalam media 1/2 MS cair dengan atau tanpa penambahan Thidiazuron dan Casein hydrolysate telah menghasilkan bentukan embriosomatik globular, hati dan torpedo setelah 6 bulan inkubasi. Kata Kunci : Manggis, Fase Embriosomatik, Thidiazuron, Medium 1/2 MS Cair
\end{abstract}

\begin{abstract}
One of the problems related to the establishment of mangosteen plantation is to obtain seedlings throughout the year, which can be solved by micropropagation. The propagation of Mangosteen was done through somatic embryogenesis. The objective of this study was to determine the effect of Thidiazuron concentration in 1/2 MS medium to achieve somatic embryo stages of mangosteen seed. The study consisted of two experiments. Experiment 1: The embryogenic callus c.a.1 g derived from MS solid medium containing of Thidiazuron (0,1; 0,5; dan 1 mg/l) and 2,4-Dichlorophenoxy acetic acid (4,6,8 dan $10 \mathrm{mg} /$ l) was subcultured into 1/2 MSO liquid medium. 2). The embryogenic callus from the previous medium were subcultured into 1/2 MS liquid medium containing Thidiazuron (0, 1, 2, 4 dan $8 \mathrm{mg} / \mathrm{L})$ and Casein hydrolysate $500 \mathrm{mg} / \mathrm{L}$. The results showed that cell suspension were developed after mangosteen embryogenic callus subcultured into 1/2 MSO liquid medium. Somatic embryo stages such as globular, heart and torpedo were formed after the calli derived from the previous 1 1 MS solid medium containing $10 \mathrm{mg} / \mathrm{L} 2,4-D$ and $1 \mathrm{mg} / \mathrm{L}$ Thidiazuron were subcultured into $1 / 2 \mathrm{MSO}$ liquid medium in 8 weeks. Cell suspension in 1/2 MS liquid medium with or without the addition of Thidiazuron and Casein hydrolysate has induced the formation of embryo somatic stages such as globular, heart and torpedo after 6 months of incubation.

Keywords: Mangosteen, Somatic Embryo Stage, Thidiazuron, 1² MS Liquid Medium
\end{abstract}

\section{PENDAHULUAN}

Manggis (Garcinia mangostana L.) merupakan tanaman buah tropis yang banyak ditemukan di hutan hujan tropis di Asia Tenggara seperti Thailand, Malaysia, Indonesia dan Philipina yang kemudian didomestikasi sebagai tanaman pekarangan atau tanaman tepi jalan (Osman dan Milan, 2006). Hampir semua bagian tanaman manggis dapat dimanfaatkan. Buah manggis selain dikonsumsi segar juga diproses menjadi berbagai produk seperti selai, sirup, perasa jus dan bir (Osman dan Milan, 2006). Antioksidan xanthones telah diisolasi dari pericarp, buah, kulit kayu dan daun. Kandungan xanthones dari manggis seperti á, â- dan ã mangostins, garcinone E, 8- deoxygartanin dan gartanin menunjukkan aktivitasnya sebagai 
antioksidan, anti tumor, anti nyeri, anti alergi, anti bakteri, anti jamur dan anti virus (Suksamrarn et al., 2006; Pedraza-Chaverri et al., 2008).

Permintaan manggis semakin meningkat karena dimanfaatkan sebagai bahan produk kesehatan.Rasa buah yang lezat menyebabkan buah ini mendapat julukan sebagai ratu buah.Permintaan manggis yang meningkat tidak diiringi dengan produksinya disebabkan manggis masih diusahakan secara konvensional.

Pengusahaan manggis dalam skala perkebunan dengan kualitas seragam terkendala oleh pertumbuhan tanaman yang lambat, perakaran yang lemah karena terbatasnya rambut akar, masa berbuah dwi tahunan dan jumlah biji layak tanam yang sedikit per buah menyebabkan ketersediaan bahan tanam yang sedikit sepanjang tahun. Alternatif untuk memproduksi bahan tanam manggis adalah melalui perbanyakan in vitro.

Selain organogenesis, perbanyakan in vitro dapat menggunakan embriogenesis somatik. Teknik ini lebih menguntungkan dibanding organogenesis karena plantlet yang dihasilkan lebih banyak, tunas dan akar diperoleh sekaligus dalam satu plantlet tanpa melalui tahap pengakaran. Usaha mendapatkan embrio somatik telah dilakukan dengan mengkulturkan biji manggis dalam medium mengandung auksin (Te-chato et al. 1995) tetapi belum berhasil.Embrioegenesis somatik didefinisikan sebagai proses perkembangan aseksual yang menghasilkan embrio dari sel-sel soma atau tubuh. Fase perkembangan seperti globular, hati, torpedo dan embrio yang diperoleh melalui embriogenesis somatik adalah sama seperti proses embriogenesis yang terjadi secara alami pada tanaman. Embriogenesis somatik dapat terjadi secara langsung yaitu embrio tumbuh dari jaringan eksplan seperti pada jeruk atau embriogenesis somatik tak langsung melalui fase kalus atau suspensi sel. Rineksane (2012) telah berhasil menginduksi embrio somatik fase globular dan torpedo dalam kultur suspensi atau kultur cair 1/2 MS dengan penambahan 1, 3 dan $9 \mathrm{mg} / 1$ Thidiazuron. Namun demikian, embriosomatik manggis belum diperoleh. Rasio konsentrasi auksin yang tinggi terhadap konsentrasi sitokinin dalam medium akan menginisiasi pembentukan sel embriogenik yaitu sel yang membelah dengan cepat, berukuran kecil, kandungan sitoplasma yang padat, nucleus besar, vakuola kecil dan adanya senyawa pati terlarut. Selain auksin, penggunaan sitokinin seperti thidiazuron dapat menginduksi embriogenesis somatik pada tanaman berkayu.Penelitian ini akan menguji penggunaan Thidiazuron dengan konsentrasi berbeda dalam medium $1 / 2$ MS untuk mencapai fase embriosomatik manggis dari kalus asal biji.

\section{BAHAN DAN METODE}

Penelitian ini dilakukan di laboratorium Kultur In Vitro, Fakultas Pertanian, Universitas Muhammadiyah Yogyakarta. Bahan tanam yang digunakan berupa kalus embriogenik manggis asal biji yang ditanam dalam medium $1 / 2 \mathrm{MS}+10 \mathrm{mg} / 1$ 2,4-D + $1 \mathrm{mg} / \mathrm{l}$ Thidiazuron yang diperoleh dari penelitian Rineksane dkk (2013). Biji manggis yang digunakan adalah varietas Kaligesing dari Purworejo, Jawa Tengah. Pencapaian fase embriosomatik dari kultur padat ke kultur cair dilakukan melalui dua eksperimen. Eksperimen 1 : Kalus embriogenik seberat $1 \mathrm{~g}$ dari medium MS padat yang mengandung Thidiazuron $(0,1 ; 0,5$; dan $1 \mathrm{mg} / \mathrm{l})$ dan 2,4-Dichlorophenoxy acetic acid (4,6,8 dan $10 \mathrm{mg} / \mathrm{l}$ ) hasil penelitian Rineksane dkk (2013) disubkultur ke dalam medium 1/2 MSO cair. Kultur cair tersebut diinkubasi di atas shaker 
dengan kecepatan $125 \mathrm{rpm}$. Eksperimen 2: Kalus embriogenik seberat $1 \mathrm{~g}$ dari medium MS padat yang telah dihomogenisasi dalam medium $1 / 2$ MSO cair selama 2 minggu, disubkultur ke dalam medium $1 / 2$ MS cair yang mengandung $\operatorname{TDZ}(0,1,2,4$ dan $8 \mathrm{mg} / \mathrm{L})$ dan Casein hydrolysate $500 \mathrm{mg} / \mathrm{L}$. Modifikasi konsentrasi sitokinin TDZ dan penambahan senyawa $\mathrm{N}$ organik Casein hydrolysate dalam medium $1 / 2$ MS cair dilakukan untuk meningkatkan persentase embrio somatik yang dihasilkan. Subkultur dan penggantian medium cair dilakukan setiap 4 minggu untuk meregenerasi kalus embriogenik menjadi fase globular, hati, torpedo dan embrio somatik.Eksperimen 2 dilaksanakan menggunakan rancangan acak kelompok lengkap (RAKL) dengan 5 perlakuan, setiap perlakuan diulang 5 kali, sehingga total unit perlakuan adalah 25 botol.

\section{HASIL DAN PEMBAHASAN}

\section{Pencapaian Fase Embriosomatik Manggis dalam Medium 1/2 MSO Cair}

Kalus yang diperoleh dari eksplan biji yang ditanam pada medium padat disubkultur agar kalus memiliki sifat embriogenik yang ditunjukkan oleh tekstur kalus remah, mudah dipisahkan dan berwarna putih kekuningan (Rineksane dkk, 2013). Kalus embriogenik hasil subkultur satu kali tersebut kemudian digunakan sebagai eksplan dalam kultur medium cair. Medium cair digunakan karena tahap pembentukan embrio somatik manggis diharapkan terjadi secara tidak langsung melalui kultur suspensi sel. Kultur suspensi sel didefinisikan sebagai pertumbuhan sel tunggal atau sekumpulan sel dalam medium cair (Gamborg dan Phillips, 1995). Kultur suspensi dari kalus remah dapat digunakan untuk menginduksi embrio somatik (Dodds dan
Roberts, 1982; Razdan, 2005) pada medium dengan kandungan senyawa yang sesuai. Sel-sel tunggal akan diperoleh dalam kultur cair karena gerakan shaker dapat memisahkan sel dari kalus embriogenik. Kemudian karena adanya auksin, sitokinin bahkan senyawa nitrogen, sel-sel tersebut akan membelah dan apabila terjadi proses embriogenesis, maka dari pembelahan dan diferensiasi sel-sel tersebut akan terbentuk struktur embriosomatik yang meliputi struktur globular, hati, torpedo dan embrio.

Kultur cair dalam penelitian ini diinkubasi selama 8 minggu. Berdasar hasil penelitian, semua kalus dari medium yang berbeda pada kultur padat, setelah disubkultur ke medium 1/2 MSO cair mampu membentuk suspensi sel. Hasil pengamatan visual menunjukkan bahwa sel-sel terpisah dari eksplan kalus dan terdispersi dalam medium cair menjadi kultur suspensi (Gambar 1). Kemudian pengamatan dilakukan di bawah mikroskop terhadap sampel yang diambil dari kultur suspensi, untuk mengamati strukturstruktur embrio yang terbentuk.

Berdasar pengamatan dari kultur suspensi dalam medium $1 / 2$ MSO cair, diketahui bahwa tidak semua kalus embriogenik dari medium $1 / 2$ MS padat yang ditambah thidiazuron dan 2,4-D dapat membentuk struktur embrio berupa globular, hati dan torpedo. Fase globular, hati dan torpedo yang diperoleh pada penelitian ini berasal dari suspensi sel yang diperoleh dari kalus yang sebelumnya ditumbuhkan pada medium $1 / 2$ MS padat yang mengandung $1 \mathrm{mg} / \mathrm{L}$ TDZ dan 10 mg/L 2,4-D (Gambar 2). Kalus yang disubkultur ke dalam medium $1 / 2$ MSO cair sudah membentuk fase globular, hati dan torpedo dalam waktu 8 minggu karena kalus sudah mengandung zat pengatur tumbuh thidiazuron dan 2,4-D yang cukup tinggi yang diperoleh dari medium kultur padat. 


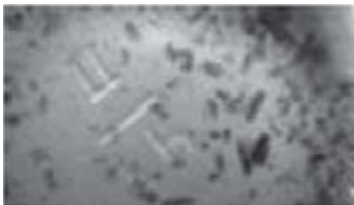

A

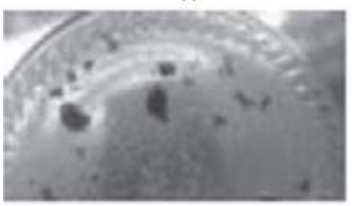

E

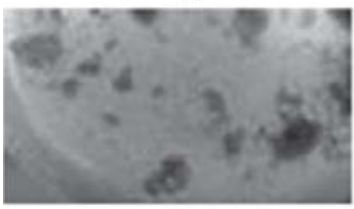

।

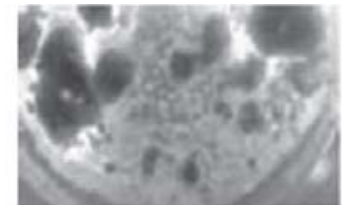

B

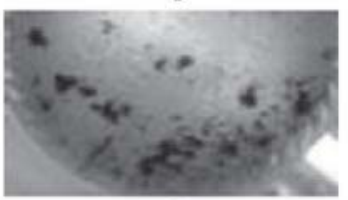

$\mathrm{F}$

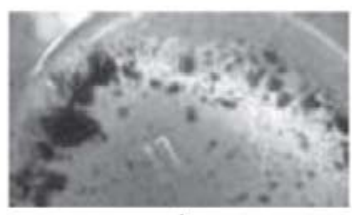

」

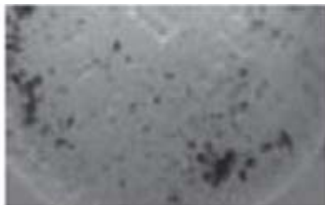

c

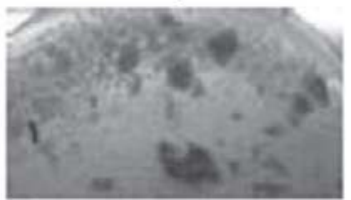

G

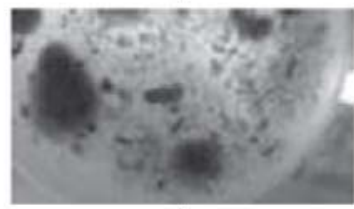

K

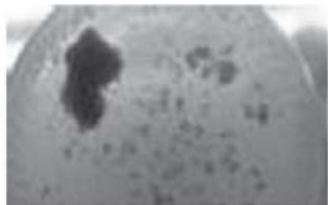

D

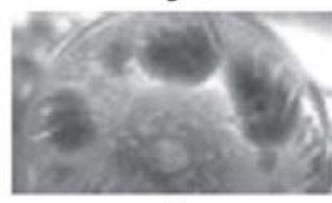

H

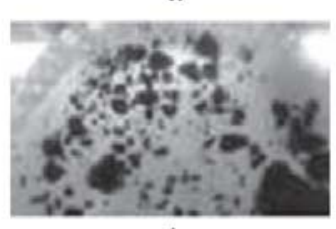

$\mathrm{L}$

Keterangan:

Kode a - 1 pada gambar, menunjukkan kombinasi Thidiazuron dan 2,4-D yang ditambahkan ke dalam medium padat, asal dari kalus embriogenik yang disubkultur ke medium $1 / 2$ MS cair
a. TDZ 0,1 mg/l + 2,4-D $4 \mathrm{mg} / \mathrm{l}$
g. $T D Z 0,5 \mathrm{mg} / \mathrm{l}+2,4-D 8 \mathrm{mg} / \mathrm{l}$
b. TDZ 0,1 mg/l + 2,4-D $6 \mathrm{mg} / \mathrm{l}$
h. TDZ 0,5 mg/l + 2,4-D $10 \mathrm{mg} / \mathrm{l}$
c. $\quad T D Z 0,1 \mathrm{mg} / \mathrm{l}+2,4-D 8 \mathrm{mg} / \mathrm{l}$
i. $T D Z 1 \mathrm{mg} / \mathrm{l}+2,4-D 4 \mathrm{mg} / \mathrm{l}$
d. TDZ 0,1 mg/l + 2,4-D $10 \mathrm{mg} / \mathrm{l}$
e. TDZ 0,5 mg/l + 2,4-D $4 \mathrm{mg} / \mathrm{l}$
i. $\quad$ TDZ $1 \mathrm{mg} / \mathrm{l}+2,4-D 6 \mathrm{mg} / \mathrm{l}$
f. TDZ 0,5 mg/l + 2,4-D $6 \mathrm{mg} / \mathrm{l}$
k. $T D Z 1 \mathrm{mg} / \mathrm{l}+2,4-D 8 \mathrm{mg} / \mathrm{l}$
I. TDZ $1 \mathrm{mg} / \mathrm{l}+2,4-D 10 \mathrm{mg} / \mathrm{l}$

Gambar 1. Fase Embriosomatik yang Terbentuk pada Medium 1⁄2 MSO Cair setelah Inkubasi Selama 8 Minggu

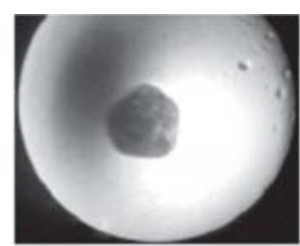

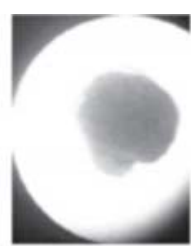

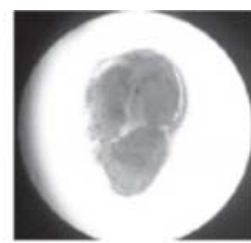

Gambar 2. Struktur embrio somatik (a. globular, b. hati, c. torpedo) yang diperoleh setelah inkubasi suspensi selmanggis dalam medium $1 \frac{1}{2}$ MSO selama 8 minggu

Pencapaian fase globular dan torpedo dari kalus remah pada penelitian ini yang terbentuk setelah 8 minggu, lebih cepat jika dibandingkan dengan hasil penelitian Rineksane (2011) yang menyatakan bahwa sel suspensi manggis mengalami pembelahan dan hanya terbentuk kluster sel setelah inkubasi selama 10 bulan. Fase globular, hati maupun torpedo tidak terbentuk pada kultur suspensi tersebut. Namun demikian, struktur embrio belum diperoleh pada tahap penelitian ini, diduga karena pembentukan struktur embrio memerlukan waktu inkubasi yang lebih lama.

\section{Pencapaian Fase Embriosomatik Manggis dalam Medium Cair + ZPT}

Selain menggunakan medium $1 / 2$ MSO, kalus embriogenik yang telah dihomogenkan dalam medium 1/2 MSO selama 2 minggu juga 
disubkultur ke medium cair dengan perlakuan penambahan $\operatorname{TDZ}(0,1,2$, 4 dan $8 \mathrm{mg} / \mathrm{L})$ dan Casein hydrolysate $500 \mathrm{mg} / \mathrm{L}$ (Gambar 3).

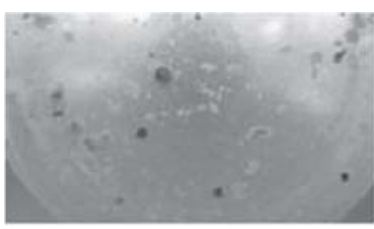

A

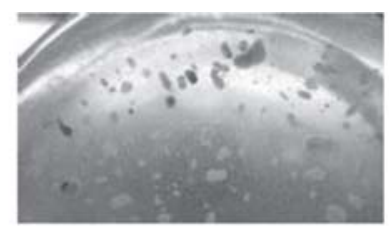

Gambar 3. Kultur Suspensi Sel dalam Media $1 / 2$ MS cair + TDZ + Casein Hydrolisate Setelah Inkubasi Selama 6 Bulan

Kalus embriogenik dari eksplan potongan biji manggis yang sudah bertekstur remah dan mencirikan karakteristik embriogenik digunakan sebagai eksplan pada induksi dan regenerasi embrio somatik dalam medium cair. Sel-sel akan terlepas dari kalus remah yang diinkubasi dalam medium cair. Sel tunggal yang berada dalam kultur suspensi sel tersebut mengalami pembelahan secara simultan dan membentuk struktur embrio somatik seperti globular, hati dan torpedo. Medium cair digunakan dalam penelitian ini karena apabila sel tunggal telah diperoleh dari suspensi sel, maka regenerasi sel tersebut menjadi struktur embrio somatik lebih cepat dibandingkan regenerasi embrio somatik pada medium padat. Kemampuan regenerasi sel dalam kultur cair lebih cepat dibandingkan kultur padat karena dalam kultur cair setiap permukaan dari eksplan dapat menyerap unsur hara dan zat pengatur tumbuh dari medium, sehingga mendorong pertumbuhan dan regenerasi yang lebih cepat. Sebaliknya eksplan yang ditanam pada medium padat hanya menyerap unsur hara dan zat pengatur tumbuh dalam medium dari bagian eksplan yang menempel pada medium saja, sehingga kecepatan tumbuh eksplan lebih lambat dari eksplan dalam medium cair.

Penggunaan sitokinin dan senyawa nitrogen seperti Casein hydrolisate dalam medium menginduksi pembelahan, pembesaran dan perkembangan sel mencapai fase embriosomatik. Hasil penelitian menunjukkan bahwa kalus embriogenik yang disubkultur dari medium $1 / 2$ MSO cair ke media cair + Thidiazuron dan Casein hydrolisate membentuk fase-fase embriosomatik : globular, hati dan torpedo setelah inkubasi selama 6 bulan (Gambar 4).

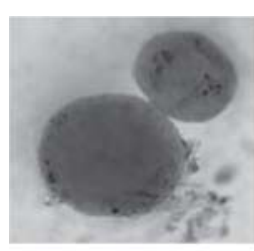

A

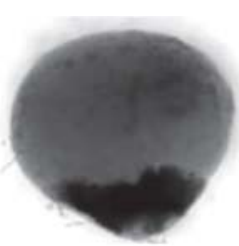

B

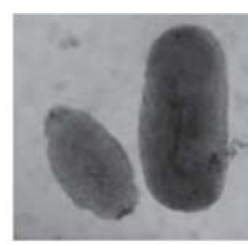

C
Gambar 4. Struktur Embrio Somatik (A. Globular, B. Hati, C. Torpedo) yang Diperoleh Setelah Inkubasi Suspensi Sel Manggis dalam Medium 1/2 MS Cair dengan Penambahan Thidiazurondan Casein Hydrolysate Selama 6 Bulan

Hasil penelitian ini meskipun menggunakan biji manggis dari lokasi yang berbeda (Manggis varietas Kaligesing, Purworejo), dilakukan di laboratorium yang berbeda dan konsentrasi thidiazuron yang dimodifikasi, telah menghasilkan fase embriosomatik yang sama (globular, hati, torpedo) sebagaimana diperoleh dari penelitian Rineksane et al (2012) setelah 6 bulan pengamatan. Namun demikian embriosomatik manggis juga belum diperoleh dari penelitian ini.Thidiazuron maupun Casein hydrolysate yang digunakan belum dapat mendorong atau menginduksi pencapaian fase akhir embriosomatik. Oleh karena itu penggunaan senyawa untuk maturasi atau pematangan embriosomatik perlu dicoba pada 
penelitian berikutnya sehingga embriosomatik manggis dapat diperoleh.

Thidiazuron telah menginduksi perubahan sel tunggal dalam kultur suspensi sehingga membelah dan mencapai fase embriosomatik torpedo. Penggunaan thidiazuron untuk inisiasi dan pencapaian fase embriosomatik dari kultur suspensi sel juga telah dilaporkan oleh Deo et al (2010) yang mengkulturkan Colocasia esculenta dalam medium cair dengan penambahan $1 \mathrm{mg} /$ 1 Thidiazuron; 0,5 mg/1 2,4-D dan $800 \mathrm{mg} / \mathrm{l}$ glutamin.

Kultur tersebut juga dapat membentuk suspensi sel, namun struktur embrio somatik belum terbentuk.Selain karena waktu inkubasi yang kurang lama, penambahan TDZ ke dalam medium regenerasi diduga menyebabkan penghambatan terhadap pembentukan struktur embrio. Sebaliknya kalus yang disubkultur ke dalam medium $1 / 2$ MSO cair sudah membentuk struktur embrio dalam waktu 8 minggu karena kalus sudah mengandung zat pengatur tumbuh endogen yang diperoleh dari medium kultur padat. Hal ini terbukti bahwa struktur embrio yang diperoleh pada penelitian ini berasal dari suspensi sel yang diperoleh dari kalus yang sebelumnya ditumbuhkan pada medium 1/2 MS padat yang mengandung $10 \mathrm{mg} / \mathrm{L}$ 2,4-D dan 1 mg/L TDZ. Pembentukan suspensi dari kalus remah pada penelitian ini yang terbentuk setelah 8 minggu lebih cepat jika dibandingkan dengan hasil penelitian Rineksane (2011) yang menyatakan bahwa kultur suspensi manggis diperoleh setelah 10bulan inkubasi.

Hasil penelitian ini menunjukkan kecepatan multiplikasi sel yang lebih cepat dibanding penelitian yang dilakukan oleh Rineksane et al. (2012). Pada penelitian ini, inkubasi kalus dalam medium cair selama 4 minggu sudah dapat menghasilkan kultur suspensi dengan konsentrasi tinggi, ditunjukkan oleh kepekatan dan warna kultur suspensi. Suspensi nampak pekat dengan warna kekuningan, menunjukkan konsentrasi sel yang tinggi. Penggunaan eksplan kalus embriogenik sebanyak 1 gram dalam medium cair berpengaruh terhadap kecepatan multiplikasi dan regenerasi sel manggis.

Kecepatan diferensiasi sel menjadi struktur embriosomatik berupa struktur globular, hati dan torpedo yang diperoleh setelah suspensi sel diinkubasi selama 8 minggu. Pada penelitian sebelumnya, diperlukan waktu 6 bulan untuk memperoleh struktur embrio somatik tersebut dan jumlahnya lebih sedikit dibandingkan yang diperoleh pada penelitian ini.

\section{SIMPULAN}

Kalus embriogenik yang disubkultur ke dalam medium $1 / 2$ MSO cair mampu membentuk kultur suspensi sel. Struktur embrio somatik berupa globular, hati dan torpedo telah terbentuk dalam waktu 8 minggu pada suspensi sel yang diperoleh dari kalus yang sebelumnya ditumbuhkan pada medium $1 / 2$ MS padat yang mengandung $10 \mathrm{mg} / \mathrm{L}$ 2,4-D dan $1 \mathrm{mg} / \mathrm{L}$ TDZ.

Kultur suspensi dalam media $1 / 2$ MS cair dengan atau tanpa penambahan Thidiazuron dan Casein hydrolysate telah menghasilkan bentukan embriosomatik globular, hati dan torpedo setelah 6 bulan inkubasi.

\section{UCAPAN TERIMA KASIH}

Penulis menyampaikan terima kasih kepada Direktorat Jenderal Pendidikan Tinggi melalui Hibah Fundamental tahun 2014 dengan nomor : 1314/K5/KM/2014.

\section{DAFTAR PUSTAKA}

Dodds, J.H., and L.W. Roberts. 1982. Experiments in Plant Tissue Culture Cambridge University Press, Cambridge. 178p. 
Gamborg, O.L., and G.C. Phillips. 1995. Plant Cell, Tissue and Organ Culture Fundamental Methods Springer-Verlag, Berlin Heidelberg. 358p

Osman, M. and A.R. Milan. 2006. Mangosteen-Garcinia mangostana. Southampton Centre for Underutilised Crops. University of Southampton.Southampton, UK. 170p.

Pedraza-Chaverri, J., N. Cardenas-Rodriguez, M. Orozco-lbarra and J.M. Perez-Rojas.2008. Medicinal properties of mangosteen (Garcinia mangostana). Food and Chemical Toxicology 46:3227 $-3239$.

Razdan, M.K. 2005.Introduction to Plant Tissue Culture.2nd ed. Science Publishers, Inc, New Hampshire. 375p.

Rineksane, I.A. 2011. Embriogenesis, Organogenesis and Assessment of Somaclonal Variations in Mangosteen (Garcinia mangostana L.).PhD Thesis. Universiti Putra Malaysia

Rineksane,I.A., M.A. Kadir, S. Kadzimin and F.Q. Zamaruzaman 2012. In vitrodevelopment of embryogenic calli and embryogenic stages in suspension cultures of mangosteen (Garcinia mangostana L.). Journal of Medical Plants Reseach 6 (13):2549 -2559 .

Rineksane, I.A., W. Aprillyastuti dan Agung Astuti. 2013. Pengaruh Jenis Eksplan, Thidiazuron dan 2,4-D terhadap Induksi Kalus Embriogenik Manggis (Garcinia mangostana L.) pada Medium Setengah MS. Prosiding Seminar Ilmiah Perhorti 2013, Vol.1. ISBN 978-979-25-1267-0.Perhimpunan Hortikultura Indonesia.

Suksamrarn, S., O. Komutiban, P. Ratananukul, N. Chimnoi, N. Lartpornmatulee and A. Suksamrarn. 2006. Cytotoxic prenylated xanthones from the young fruit of Garcinia mangostana. Chemical Pharmacy Bulletin 54:301-305.

Te-chato S, M. Lim and P. Suranilpong. 1995. Embryogenic callus induction in mangosteen (Garcinia mangostana L). Songklanarin Journal of Science and Technology 17(2):115-20. 